\title{
Transport of Orally Administered Rabbit IgG into Blood Circulation of Goldfish
}

\author{
Osamu Nakamura, * Makito Kobayashi,* Yuzuru Suzuki,* \\ Katsumi Aida,* and Isao Hanyu* \\ (Received April 18, 1990)
}

\begin{abstract}
Rabbit antiserum to salmon-gonadotropin (sGtH) was orally administered to goldfish. The plasma concentration of anti-sGtH rabbit IgG in goldfish was estimated by antigen-binding activity of the blood plasma to ${ }^{125} \mathrm{I}$ labeled sGtH, and was expressed as percentage to that of original antiserum. After oral administration, the concentration of anti-sGtH rabbit IgG in goldfish plasma markedly increased, and reached a maximum value of $1.27 \%$ at 12 hours. This value subsequently decreased gradually to $0.57 \%$ at 72 hours. The above results demonstrate that orally administered rabbit IgG is transported from the alimentary canal to blood circulation in goldfish, preserving its antigen-binding activity. In the group of fish to which was administered $1 \%$ diluted antiserum, the value of anti-sGtH rabbit IgG concentration was approximately $1 \%$ of that of the group administered $100 \%$ antiserum. This fact suggests that protein uptake is not a reaction for excessive protein but occurs even when a small amount of protein was ingested.
\end{abstract}

The intestinal epithelium of fish generally possesses the ability to ingest intact macromolecular proteins. ${ }^{1,2)}$ More recently, it has been shown that the absorbed portein can be transported into the blood circulation. ${ }^{3-8)}$

The phenomenon of intact protein uptake is considered to have the potential to lead to significant technical improvements in aquaculture. For example, the oral administration of a physiologically active protein such as peptide hormone or immunoglobulin is possible by such means. Thus, oral treatment can be of practical value in fish culture. Active proteins may be administered more easily and economically by addition to ordinary feed; this frees the aquaculturist from the necessity of the exchange of water or the handling of fish that is required in other methods.

We previously examined the oral administration of extract of mature salmon pituitary to male and female goldfish Carassius auratus., ${ }^{5,6)}$ It was found that salmon gonadotropin ( $\mathrm{sGtH}, \mathrm{MW} \mathrm{ca}$ 48,000 ) from pituitary extract was transfported into the general blood circulation of goldfish. It was additionally demonstrated that the sGtH absorbed into the circulation in this manner can induce milting and ovulation in goldfish.

This study was designed to examine the feasibility of passive immunization, considered to be one of several significant applications of oral treatment.
We investigated the oral administration of antisGtH rabbit serum in goldfish revealing that rabbit $\mathrm{IgG}$, which constitutes the major class of immunoglobulin in mammalian serum, can be transported into the blood circulation of goldfish, with the preservation of its specific antigen binding activity.

\section{Materials and Methods}

Fish

Goldfish weighing 32 to $100 \mathrm{~g}$ were used. Three days prior to experimentation, 60 fish were selected at random and acclimated at $25^{\circ} \mathrm{C}$ in $20 \mathrm{l}$ glass aquaria without feed.

\section{Antiserum}

Rabbit antiserum against $\mathrm{sGtH}$ prepared by Kobayashi et al. $^{9)}$ was used.

\section{Oral Administration}

Fish were divided into six groups (eight to ten fish per group), three of which were used for a short term experiment (Exp. 1). Fish were orally intubated with $100 \%$ antiserum (group 1-A), 1\% antiserum diluted with $0.9 \% \mathrm{NaCl}$ (group 1-B) or $0.9 \% \mathrm{NaCl}$ only as a control (group 1-C), respectively. The dose was $0.2 \mathrm{ml} / 100 \mathrm{~g}$ body weight. Remaining three gorups were used for a long term

* Department of Fisheries, Faculty of Agriculture, University of Tokyo, Yayoi, Bunkyo, Tokyo 113, Japan (中村 悠, 小林牧人, 跉木 培, 会田勝美. 羽生 功: 東京大学農学部水産学科). 
experiment (Exp. 2) and orally administered the same as the group of Exp. 1. A method of oral administration has been already reported. ${ }^{5,8)}$

\section{Blood Sampling}

Prior to administration of anti-sGtH, the experimental animals were anesthetized with $0.02 \%$ tricainemethansulfonate, and initial blood samples $(0.15 \mathrm{ml})$ were taken from the caudal vasculature using heparinized syringes and needles. Serial blood samples were taken in the same manner, at 1,3 , and 6 hours following administration in Exp. 1, and at 6, 12, 24, 48, and 72 hours in Exp. 2. The blood was centrifuged at $1,500 \mathrm{~g}$ for $30 \mathrm{~min}$ and the separated plasma was stored at $-20^{\circ} \mathrm{C}$ until further use.

\section{Assay for Anti-Salmon GtH}

To measure the concentration of anti-sGtH rabbit IgG in the goldfish plasma, the following method was applied.

sGtH labeled with ${ }^{125}$ I was prepared in the same manner as reported by Kobayashi et al. ${ }^{\text {p) }}$ The standard rabbit antiserum was dissolved in GelPBS (0.01 M phosphate buffer, pH 7.5, containing $0.1 \%$ gelatin, $0.14 \mathrm{M} \mathrm{NaCl}$, and $0.1 \%$ sodium azide) at ten concentrations in serial dilution ranging from $1 \%$ to $1.95 \times 10^{-3} \%$. A volume of goldfish plasma was also diluted with Gel-PBS at ten or one-hundred-fold concentrations. Firstly, $50 \mu l$ of the standard antiserum or goldfish plasma was added respectively to $200 \mu \mathrm{l}$ of Gel-PBS, followed by the addition of $100 \mu l$ of labeled hormone (approximately $20,000 \mathrm{cpm}$ ), and $100 \mu l$ of EDTA-PBS (0.01 M phosphate buffer, pH 7.5, $0.14 \mathrm{M} \mathrm{NaCl}, 0.05 \mathrm{M}$ EDTA, and $0.1 \%$ sodium azide) containing $1 \%$ normal rabbit serum (NRS) to each tube. Secondly, after incubation for 24 hours at $4^{\circ} \mathrm{C}, 50 \mu \mathrm{l}$ of anti-rabbit IgG goat IgG diluted adequately with EDTA-PBS was added to precipitate the immunocomplex. Thirdly, following an additional overnight incubation at $4^{\circ} \mathrm{C}$, ${ }^{128} \mathrm{I}$ bound to the immunocomplex was separated from free ${ }^{125} \mathrm{I}$ by centrifugation at $1,500 \mathrm{~g}$ for 30 min and subsequent aspiration of supernatant. Finally, ${ }^{125} \mathrm{I}$ radioactivity in the precipitate was counted using a $\gamma$-counter.

Parallelism of the dose response curves of twofold diluted plasma samples to the standard curve was tested by analysis of varinace.

\section{Results}

\section{Assay System}

The standard curve obtained from this assay is shown in Fig. 1. The intra- and interassary coefficients of variation were $9.70(n=5)$ and 17.55 $(n=3)$ respectively at an antiserum concentration

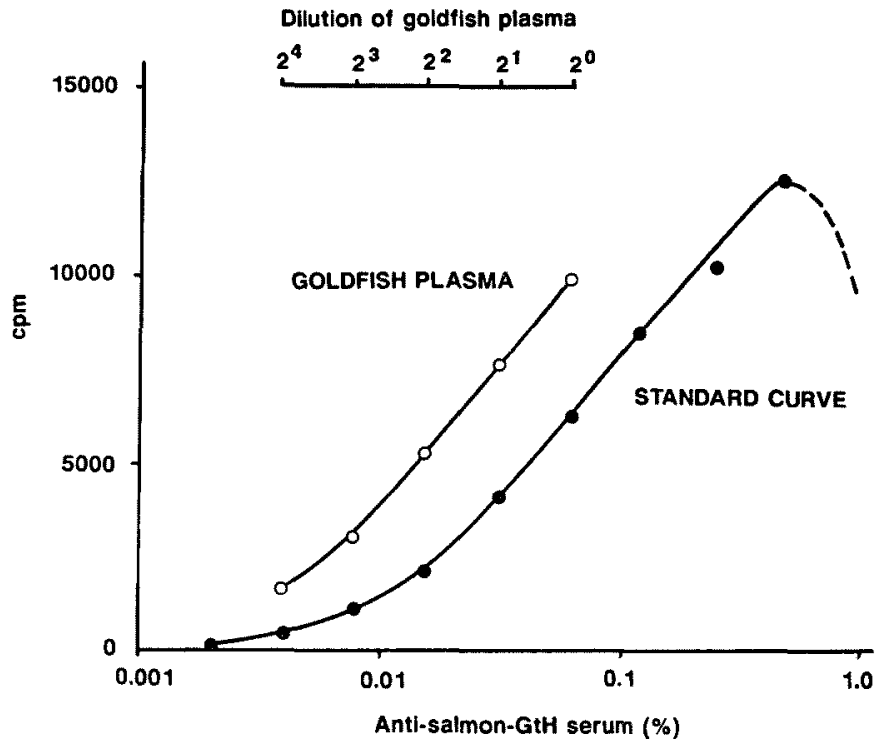

Fig. 1. Dose response curves for anti-salmon-GtH rabbit antiserum. (-) denote the antisalmon-GtH rabbit serum two-fold diluted from $1 \%$, and $(0-0)$ denote the plasma of goldfish at 6 hours after administration of antiserum. Goldfish plasma was also two-fold diluted. 


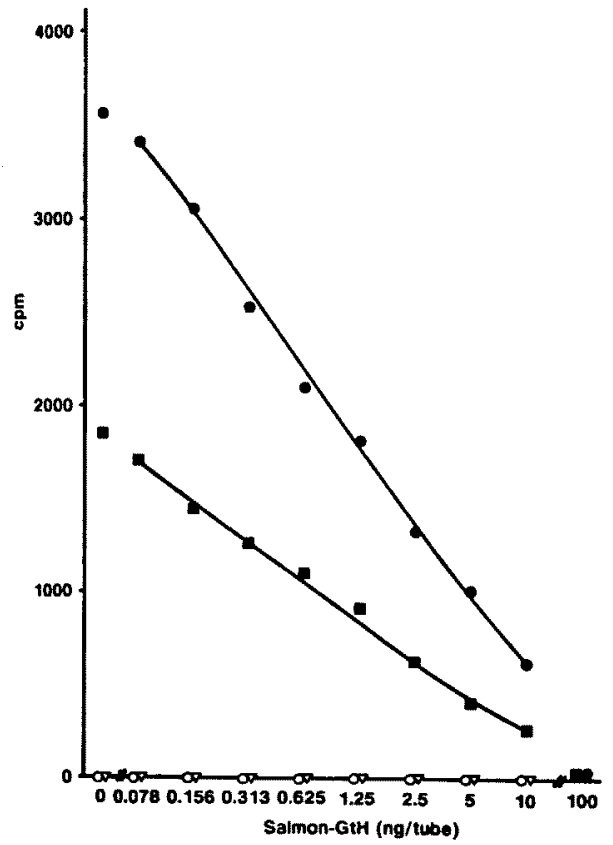

Fig. 2. Dose response competition curves for salmon $\mathrm{GtH}$ with goldfish plasma which was obtained $6 \mathrm{~h}$ after oral administration. (-) and ( $(\mathbf{0}-\mathbf{m})$ denote the plasma of goldfish treated with antisalmon-GtH rabbit serum, diluted $\times 20$ and $\times 50$ respectively. $(O-O)$ and $(\nabla-\nabla)$ denote the nondiluted plasma of goldfish treated with NRS and of intact fish respectively.

of $6.25 \times 10^{-2} \%$. The dose response curve of the two-fold diluted goldfish plasma obtained 6 hours after the administration of the antiserum was parallel to the standard curve, showing that this assay system can be considered valid for application in this experiment. However, at high doses of antiserum (over $0.5 \%$ ), the counts tended to decrease, probably because of the prozone phenomenon. Therefore, adequate dilution of sample plasma is needed to prevent this phenomenon. The validity of this assay system was also confirmed by showing that the reaction was inhibited by competition with unlabeled salmon $\mathrm{GtH}$ as shown in Fig. 2.

\section{Short Term Experiment (Exp. I)}

As shown in Fig. 3, anti-S-GtH rabbit IgG activity appeared in the goldfish plasma as early as 1 hour after the administration of undiluted antiserum (group 1-A). The concentration of antibodies in the goldfish plasma increased until the end of the experiment; at 6 hours, reached

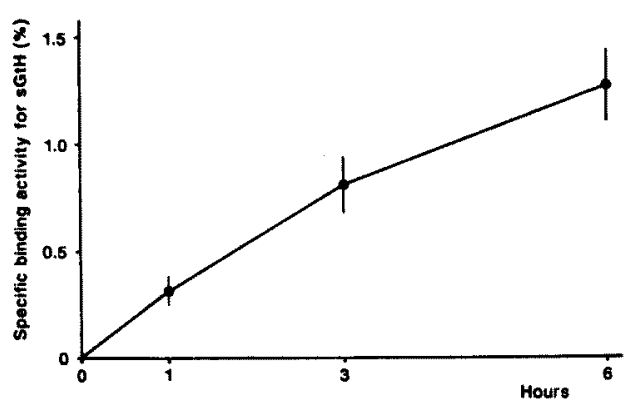

Fig. 3. Short term experiment. Changes in the level of specific binding activity for salmon GtH in goldfish plasma after oral administration of rabbit antiserum. *The specific binding activity is indicated as percentage to that of original rabbit antiserum in Figs. 3-6.

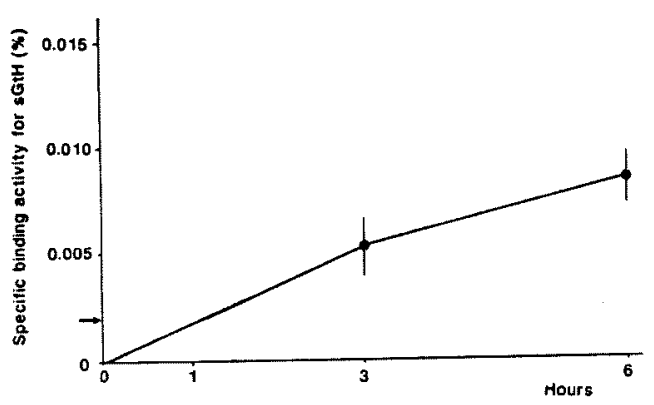

Fig. 4. Short term experiment. Changes in the level of specific binding activity for salmon GtH in goldfish plasma after oral administration of $1 \%$ diluted rabbit antiserum. The value of plasma at $1 \mathrm{~h}$ is lower than the minimum detectable level, $0.00195 \%$ (arrow).

$1.28 \%$ of the rabbit antiserum. In group $1-\mathrm{B}$, the time course of appearance of anti-sGtH rabbit IgG activity was similar to that of group 1-A, although the 1-B levels were as low as $1 / 100$ of $1-\mathrm{A}$ levels (Fig. 4). No activity was observed in the plasma of group 1-C fish and in initial samples of treated fish.

\section{Long Term Experiment (Exp. 2)}

As shown in Fig. 5, anti-sGtH rabbit IgG activity in the blood plasma of fish of group 2-A reached a maximum value of $1.27 \%$ of the original antiserum at 12 hours. Subsequently, the plasma activity decreased gradually, although the activity was still high even at 72 hours $(0.57 \%)$. In group 2-B, the time course of the appearance of antisGtH rabbit IgG activity was very similar to that of group 2-A as shown in Fig. 6, although the 2-B levels were as low as $1 \%$ of 2 -A levels. The plasma 


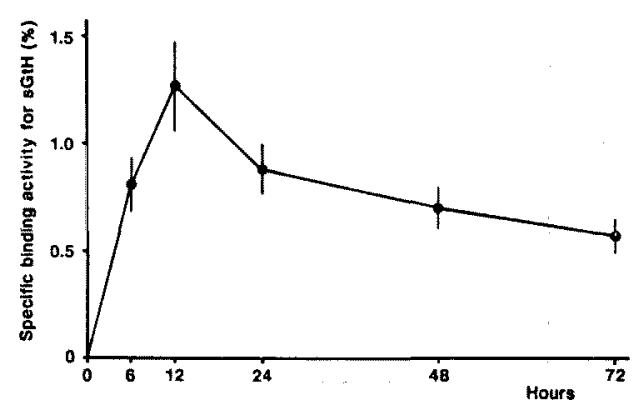

Fig. 5. Long term experiment. Changes in the level of specific binding activity for salmon GtH in goldfish plasma after administration of rabbit antiserum.

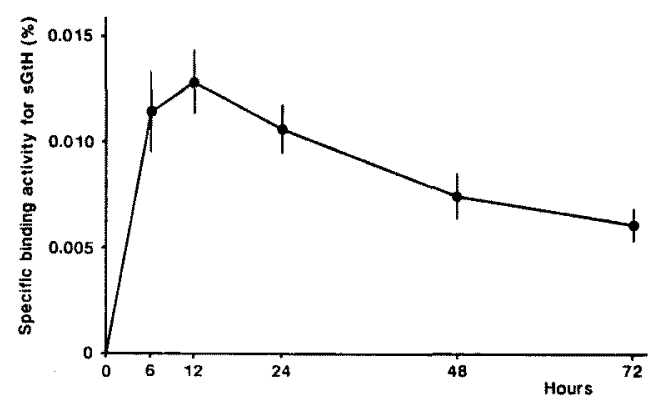

Fig. 6. Long term experiment. Changes in the level of specific binding activity for salmon $\mathrm{GtH}$ in goldfish plasma after oral administration of $1 \%$ diluted rabbit antiserum.

of group 2-C fish and of initial samples of treated fish showed no activity.

\section{Discussion}

As has been described above, anti-sGtH rabbit IgG was detected in goldfish plasma after the oral administration of anti-sGtH rabbit serum. This result demonstrates that orally administered rabbit IgG is absorbed by the alimentary canal of goldfish and is transported into the blood circulation as a nearly intact molecule retaining its specific antigen binding activity.

In the present study, the antiserum was administered as two different dosages, $100 \%$ and $1 \%$. No obvious differences were observed between these two groups regarding the time course of appearance of rabbit IgG in the blood as well as the ratio of the amount of protein absorbed to that of administered. Thus, it appears that protein uptake always occurs in the same manner, even when only a small amount of protein is administered. This is in contrast to the hypothesis of Stroband and Van der Veen, ${ }^{10}$ in which this phenomenon is regarded as a "stand-by function" for excessive protein.

On the other hand, McLean and $\mathrm{Ash}^{2)}$ have hypothesized that protein uptake has little or no nutritional importance, because the amount of absorbed protein is rather low. According to Itazawa, ${ }^{11}$ ) total plasma volume in carp is approximately $5 \mathrm{~m} l$ per $100 \mathrm{~g}$ body weight. This information was used as a factor in the estionation of the extent of absorption of administered antisGtH rabbit IgG into the bloodstream as performed in this investigation. Provided that the uptake of the $0.2 \mathrm{ml}$ administered anti-sGtH into the bloodstream is $100 \%$, resultant anti-sGtH concentrations in $5 \mathrm{~m} /$ plasma $/ 100 \mathrm{~g}$ body weight should indicate concentrations at $4 \%$ of the original antiserum. In the actual investigation, a maximum plasma concetration of $1 \%$ of administrated antiserum was detected, suggesting that the actual transport of anti-sGtH was approximately $25 \%$; however, considering that a high turnover of antisGtH may be present, the rate of transport of antisGtH may be somewhat higher. Therefore, the intact protein uptake may be of nutritional value in goldfish. If this is true, we may raise the question of how enteric and systemic immunity is developed against the penetration of antigens contained in the diet.

Goldfish which had been administered with rabbit antiserum had a high anti-sGtH plasm activity even after 72 hours. In contrast, sGtH disappeared more rapidly with levels reduced to less than $20 \%$ of the maximum value within 72 hours. ${ }^{5,0)}$ These findings indicate that the halflife of rabbit IgG in goldfish plasma is rather long compared with that of sGtH. This difference is probably due to the difference of metabolic pathways. SGtH is considered to be metabolised mainly at the gonad, as the hormone shows gonadtropic effects on this organ. On the other hand, rabbit IgG is possibly degraded mainly at the liver, spleen, and kidney as in the case of horseradish peroxidase (HRP) in the carp, ${ }^{3)}$ although HRP disappeared from plasma more rapidly in the above report.

The current study shows that it may be possible to conduct passive immunization in fish via an oral route. The longer half-life of rabbit IgG is also of advantage. The efficacy of passive immunization for fish by injection of mammalian antiserum or antibody has been demonstrated by 
several researchers. ${ }^{12-15)}$ McCarthy et al. ${ }^{14)}$ have demonstrated that the passive immunization of socheye salmon by rabbit antiserum to Aeromonas salmonicida, is effective in inducing protective immunity. Additionally, Fukuda and Kusuda $^{18)}$ have reported in yellowtail the efficacy of rabbit antibody to Pasteurella piscicida for protection against pathogens for at least $24 \mathrm{~h}$ after immunization. The therapeutic value of rabbit antiserum have also reported by Marquis and Lallier ${ }^{15)}$ who immunized brook trout passively against $A$. salmonicida at $48 \mathrm{~h}$ post-infection. On the other hand, some workers reported the inefficacy of rabbit antibody for activation of the classical pathway of complement system in fish. ${ }^{18-20)}$ Moreover, there is little knowledge concerning whether the other effector functions of mammalian antibody, such as opsonization and binding to immunocompetent cells can operate in fish. Further studies on the mechanisms of the interaction between mammalian antibody and fish immune system are needed to affirm the possibility of passive immunization.

This current study has been carried out with agastric species, i.e., species not possessing pep$\sin ^{21,22)}$ Hence, it is not yet clear whether the above results can be considered applicable to gastric species as well. McLean and Ash' ${ }^{2)}$ reported that the presence of orally administered HRP in plasma and tissue was significantly (more than 1000 -fold) greater in "agastric" carp than in "gastric" trout. On the other hand, Georgopoulou et $a .^{8)}$ reported that $6 \%$ of HRP administered into the pyloric curvature of the stomach of rainbow trout was transported into the blood circulation of fish. Therefore, the development of a more consistent manner of protein deliverance to the absorptive region of the intestine is needed to further develop practical applications of this technique to fish culture.

\section{Acknowledgements}

We thank Ms. Marcy N. Wilder for reading the manuscript. This work was supported by a Grant-in-Aid for Scientific Research from the Japanese Ministry of Education, Science and Culture.

\section{References}

1) R. Ash: in "Nutrition and Feeding in Fish" (eds. by C. B. Cowey, A. M. Mackie, and J. G. Bell), Academic Press, London, 1985, pp. 66-93.

2) E. McLean and R. Ash: J. Fish Biol, 31, 219223 (1987).

3) E, McLean and R, Ash: Comp. Biochem. Physiol, 84A, 687-690 (1986).

4) E. McLean and R. Ash: Comp. Biochem. Physiol., 88A, 507-517 (1987).

5) Y. Suzuki, M. Kobayashi, K. Aida, and I. Hanyu: J. Comp. Physiol. B, 157, 753-758 (1988).

6) Y. Suzuki, M. Kobayashi, O. Nakamura, K. Aida, and I. Hanyu: Aquaculture, 74, 379-384 (1988).

7) Y. Fujino and A. Nagai: J. Fac. Mar, Sci. Technol. Tokai Univ., 26, 155-166 (1988).

8) U. Georgopoulou, K. Dabrowski, M. F. Sire, and J. M. Vernier: Cell. Tissue Res., 251, 145152 (1988).

9) M. Kobayashi, K. Aida, H. Sakai, T. Kaneko, K. Asahina, I. Hanyu, and S. Ishii: Nippon Suisan Gakkaishi, 53, 995-1003 (1987).

10) H. W. J. Stroband and F. H. Van der Veen: $J$. Exp. Zool., 218, 149-156 (1981).

11) Y. Itazawa: in "Gyorui Seirigaku Gairon" (ed. by T. Tamura), Koseisha Kouseikaku, Tokyo, 1977, pp. 34-62.

12) L. W. Harrell, H. M. Etlinger, and H. O. Hodgins: Aquaculture, 6, 211-219 (1975).

13) Y. Fukuda and R. Kusuda: Fish Pathol, 16, 85-89 (1981).

14) D. H. McCarthy, D. F. Amend, K. A. Johanson, and J. V. Bloom: J. Fish Dis., 6, 155-174 (1983).

15) H. Marquis and R. Lallier: J. Fish Dis., 12, 233-240 (1989).

16) D. W. Legler, E. E. Evans, and H. K. Dupree: Trans. Am. Fish. Soc., 96, 237-242 (1981).

17) G.S. Ross and J. A. Jensen: J. Immunol, 110, 175-182 (1973).

18) D. K. Sakai: Nippon Suisan Gakkaishi, 47, 979991 (1981).

19) M. Nonaka, N. Yamaguchi, S. Natsuume-Sakai, and M. Takahashi: J. Immunol., 126, 14891494 (1981).

20) H. Matsuyama, M. Nakao, and T. Yano: Nippon Suisan Gakkaishi, 54, 1993-1996 (1988).

21) H. J. Vonk: Adv. Enzymol., 1, 371-403 (1941).

22) K. D. Jany: Comp. Biochem. Physiol., 53B, 31-38 (1976). 